\title{
ANÁLISE DA FREQUÊNCIA DA MUTAÇÃO C282Y NA POPULAÇÃO PARANAENSE
}

\author{
Analysis of the C282Y Mutation Frequency \\ in the Parana Population
}

\author{
Danielle Jackowski ${ }^{1}$ \\ Eduardo Santos Rebello \\ Fabio Rueda Faucz ${ }^{3}$
}

\section{Resumo}

A hemocromatose $(\mathrm{HH})$ é uma doença hereditária do metabolismo do ferro que resulta na absorção excessiva de ferro e seu acúmulo progressivo no fígado, pâncreas, coração e outros órgãos. É uma doença autossômica recessiva que se expressa mais freqüentemente e com sintomas mais severos nos homens que nas mulheres, numa relação estimada de 10:1. A mutação C282Y é descrita como a troca das bases nitrogenadas C por A no nucleotídeo 845 resultando na substituição do aminoácido cisteína por tirosina na posição 282. Apresenta-se como a mutação mais comum para hemocromatose, porém, com diferentes freqüências genotípicas entre as populações. Os estudos de prevalência da HH no Brasil são ainda muito escassos, porém, em $4 \%$ a $7 \%$ da população geral é possível encontrar um alelo mutante. A análise da freqüência da mutação C282Y na população paranaense é necessária visto que se trata da mais freqüente mutação para a $\mathrm{HH}$ em caucasóides. A finalidade deste estudo é determinar a freqüência da mutação C282Y do gene da HH na população paranaense, comparando os resultados obtidos nesta pesquisa com dados já descritos. Para tanto, as amostras foram submetidas a PCR seguido de eletroforese para confirmação da amplificação. Em seguida, foram feitas as análises através da técnica de RFLP (para caracterização dos controles) ou SSCP (para a análise das amostras). A análise da freqüência da mutação C282Y indicou num total de 289 amostras, a ocorrência de 279 indivíduos homozigotos normais (96,5\%), 1 indivíduo homozigoto mutado para a mutação C282Y (0,3\%) e 9 indivíduos heterozigotos (3,2\%).

Palavras-chave: Hemocromatose; Mutação C282Y; Gene HFE; Sobrecarga de ferro.

Bióloga pela PUCPR, e-mail: djackowski@hotmail.com

Biólogo pelo UnicenP, e-mail: dudu.biologo@ibest.com.br

Doutor em Genética pela UFPR, Professor Adjunto I Curso de Biologia PUCPR, e-mail: fabiogenetica@yahoo.com

Endereço para correspondência: Pontifícia Universidade Católica do Paraná (PUCPR) CCBS, Lab. de Genética. R. Imaculada Conceição 1155, Prado Velho, Curitiba, PR, Brasil, CEP 80251-901. 


\section{Abstract}

Hemochromatosis $(\mathrm{HH})$ is a hereditary disease of the iron metabolism that results in the increased absorption of iron and its gradual accumulation in the liver, pancreas, heart and other organs. It is an autossomic recessive disease that is expressed more frequently and with more severe symptoms in men than in women, in an estimated relation of 10:1. C282Y mutation is described as the exchange of nitrogenous bases $\mathrm{C}$ for $\mathrm{A}$ bases at nucleotides 845 resulting in the substitution of cistein for tirosine at amino acid 282 position. It is presented as the most common mutation for hemochromatosis, however, with different genotipics frequencies among populations. The prevalence of studies $\mathrm{HH}$ in Brazil are still very few, however in $4 \%$ to $7 \%$ of the general population are possible to find one alelo mutant. The analysis of the frequency of C282Y mutation in the Paraná population is necessary because it is the most frequent mutation for $\mathrm{HH}$ in caucasoids. The purpose of this study is to determine the frequency of C282Y mutation of the HH gene in the Paraná population, and compare the obtained results in this research with those described in previous work. The samples had been submitted to PCR followed by eletroforesis for amplification confirmation. After that analyses by the technique of RFLP (for characterization of the controls) or SSCP had been made (for the analysis of the samples). The analysis of the frequency of the C282Y mutation indicated in a amount of 289 samples, the occurrence of 279 normal homozygotes individuals (96,5\%), 1 individual homozygote for mutation $\mathrm{C} 282 \mathrm{Y}(0,3 \%)$ and 9 individuals heterozygotes $(3,2 \%)$.

Keywords: Hemochromatosis; C282Y mutation; HFE gene; Iron overload.

\section{Introdução}

A hemocromatose é uma doença hereditária do metabolismo do ferro que resulta na absorção excessiva de ferro e seu acúmulo progressivo no fígado, pâncreas, coração e outros órgãos com posterior dano estrutural e funcional destes (Powell et al.,1999). É uma doença autossômica recessiva que se expressa de maneira mais freqüente, precoce e severa nos homens que nas mulheres, numa relação estimada de 10:1 (Feder et al.,1996), sendo que os pacientes homens desenvolvem normalmente os sintomas entre os 40 e 60 anos de idade e as mulheres depois da menopausa. $O$ fato de a doença só se manifestar nas mulheres após a menopausa é devido ao efeito protetor da menstruação e da gravidez, onde ocorre eliminação de ferro, não permitindo seu acúmulo no organismo (MOIRAND et al., 1997).

As manifestações clínicas dependem do grau de sobrecarga de ferro. Nos primeiros anos de vida não há qualquer sintoma ou sinal. Porém, após algumas décadas, quando os depósitos de ferro tornam-se elevados, começam a surgir os primeiros sintomas que são em sua maioria muito inespecíficos e não apontam para nenhum órgão ou sistema: fadiga, fraqueza, artralgia, impotência, dor abdominal, amenorréia e perda de peso. Com a evolução da sobrecarga de ferro há um comprometimento maior dos órgãos envolvidos com o risco de desenvolver cirrose, diabetes, cardiomiopatias, artrites, hipogonadismo, hiperpigmentação da pele (Bacon et al.,1999). Estudos recentes apontam a hemocromatose como um fator de risco para o mal de Alzheimer (CONNOR et al., 2001) e para a epilepsia (IKEDA, 2001).

A descoberta do gene da hemocromatose (Feder etal.,1996) no braço curto do cromossomo 6 , na região $6 \mathrm{p} 21.3$ levou a importantes considerações sobre a doença. Atualmente, conhecido como HFE, o gene para HH assemelha-se aos do complexo principal de histocompatibilidade humano. O gene HFE codifica uma proteína transmembrana de 343 aminoácidos que se assemelha às proteínas do HLA de classe I, ambas possuindo uma região transmembrana e três domínios extracelulares $\left(a_{1}, a_{2}\right.$ e $\left.a_{3}\right)$ (LEBRON et al, 1998).

A proteína HFE participa da regulação da afinidade do receptor de transferrina, que é a proteína que transporta o ferro e está presente em vários tipos celulares. Uma vez sintetizada, a proteína HFE forma um complexo com a $b_{2}-$ microglobulina e é assim transportada para a superfície da célula, onde se fixa em proximidade com o receptor de transferrina. Seu papel é o de regular a afinidade do receptor de transferrina, controlando deste modo a quantidade de ferro que é captado por cada célula.

Duas mutações são consideradas as mais importantes devido às suas freqüências em indivíduos que apresentam hemocromatose hereditária: C282Y e H63D. Recentemente foram descritas ou- 
tras mutações que podem estar presentes em pacientes que têm o diagnóstico estabelecido para a doença, tais como: S65C, G168T, G169A, T281K, G93R, I105T, C750G, entre outras.

A principal mutação, C282Y, presente no terceiro éxon do gene HFE, é devida a uma transição de $\mathrm{G}$ para A no nucleotídeo 845, o qual substitui uma cisteína por tirosina na posição 282 do polipeptídeo. Já a mutação H63D, presente no éxon 2 , deve-se à mudança de $\mathrm{C}$ para $\mathrm{G}$ no nucleotídeo 187 que resulta na substituição da histidina por ácido aspártico na posição 63 do polipeptídeo. Embora estas duas mutações sejam as principais, C282Y é a mais freqüente enquanto que H63D parece não acarretar em maior risco de sobrecarga de ferro quando aparece isoladamente. Contudo, quando associada à mutação C282Y este risco é maior.

A mutação $\mathrm{C} 282 \mathrm{Y}$ torna a proteína $\mathrm{HFE}$ incapaz de se associar com a $\mathrm{b}_{2}$-microglobulina que, portanto, não é expressa na membrana celular levando a um aumento significativo e permanente da afinidade do receptor de transferrina. $\mathrm{Na}$ proteína com a mutação H63D, a associação com a $\beta_{2}$-microglobulina ocorre, mas há uma perda parcial de função o que leva a um aumento discreto da afinidade do receptor de transferrina.

A hemocromatose é uma das doenças genéticas mais freqüentes em várias populações, afetando em média 1 em cada 200-400 indivíduos. No Canadá, Estados Unidos, Inglaterra, França, Alemanha, Portugal entre outros países de origem caucasóide, cerca de $90 \%$ a $95 \%$ dos pacientes com hemocromatose hereditária apresentam homozigose para a mutação C282Y, porém esta relação sofre variações nas populações. Nos estudos em indivíduos europeus, a homozigosidade de $\mathrm{C} 282 \mathrm{Y}$ em pacientes com hemocromatose variou de $64 \%$ em pacientes italianos para $100 \%$ em pacientes australianos. Em pacientes ingleses e franceses a homozigosidade para $\mathrm{C} 282 \mathrm{Y}$ ocorre em $80 \%$ a $90 \%$. Entretanto, a C282Y é ausente ou tem freqüências alélicas baixas em populações não caucasianas, isto é, africanas, asiáticas e populações aborígenes australianas (MERRYWEATHERCLARKE et al., 1997).

No Brasil, os estudos de prevalência da HH são ainda muito escassos, porém é possível encontrar um alelo mutante em $4 \%$ a $7 \%$ da população geral da região Nordeste do País (GOCHEE; POWELL, 2001). Tendo em vista a heterogeneidade genética observada no Brasil, devido à grande mistura étnica de negróides, caucasóides e ameríndios, a freqüência da mutação $\mathrm{C} 282 \mathrm{Y}$ pode sofrer variação comparada a populações em outros países. Além do que, em se tratando de um país geograficamente grande, nota-se a ocorrência de diferentes freqüências regionais devido às diferentes etnias que colonizaram cada região (Bittencourt et al.,2002). Assim, a região Sul do País com ascendência caucasóide deve apresentar diferentes freqüências para a mutação C282Y quando comparadas à população da região Nordeste, por exemplo, de origem predominantemente negróide.

A ocorrência da mutação C282Y juntamente com outras mutações como H63D e S65C em indivíduos heterozigotos compostos mostram a importância da C282Y como quase que totalmente determinante para a ocorrência da hemocromatose, pois estas quando se manifestam isoladamente produzem fenótipos suaves da doença e somente associadas a $\mathrm{C} 282 \mathrm{Y}$ conferem um aumento no risco da sobrecarga de ferro. Também outras descrições confirmam esta consideração como no caso das mutações G168T e G169A que, quando herdadas com a C282Y em cromossomos diferentes, apresentam sinais da hemocromatose hereditária (PIPERNO et al., 2000).

Para a homozigosidade de C282Y, a expressão fenotípica varia desde as taxas elevadas de saturação de transferrina até os sintomas clínicos que podem mostrar-se diferentes de acordo com o sexo e a idade do paciente. Estudos apontam para uma penetrância de 95\% na sobrecarga de ferro em homens homozigotos para C282Y com mais de 40 anos de idade, sendo que $50 \%$ desses homens apresentam outros sintomas. Em homens com menos de 40 anos de idade, $80 \%$ têm sobrecarga de ferro e $12 \%$ têm sintomas adicionais. A sobrecarga de ferro é vista em $80 \%$ das mulheres homozigotas para $\mathrm{C} 282 \mathrm{Y}$ com idade superior a 40 anos, sendo que 13\% dessas têm outros sintomas. Somente 39\% das mulheres com menos de 40 anos têm sobrecarga de ferro, não apresentando sintomas adicionais. Relacionando fenótipo e sexo, as mulheres usualmente apresentam-se com fadiga e pigmentação, visto que os homens apresentam-se geralmente com cirrose e diabetes (MOIRAND et al., 1997).

A hemocromatose tem um tratamento extremamente simples baseado na retirada perió- 
dica de sangue por flebotomia, levando a uma expectativa de vida normal se a doença for diagnosticada antes do início de perigo severo para os tecidos (Niederau et al., 1996) Em pacientes identificados com a doença, porém, sem maiores complicações clínicas como cirrose hepática, a probabilidade de sobrevivência é maior, juntamente com a prevenção das complicações.

A análise da freqüência da mutação $\mathrm{C} 282 \mathrm{Y}$ na população paranaense é relevante visto que se trata da mais freqüente mutação para a $\mathrm{HH}$. Porém, vale esclarecer que a ausência de mutações não exclui o diagnóstico para a doença, pois estudos mostram que cerca de 1 a 3\% dos pacientes não apresentam nenhuma das mutações em ambos os alelos. A ausência de teste neonatal que possa detectar a ocorrência das mutações que levam a $\mathrm{HH}$ provoca uma diminuição na qualidade de vida dos indivíduos afetados, pois se ocorresse um diagnóstico prévio desses indivíduos, o tratamento para normalizar os níveis de ferro preveniria o desenvolvimento dos sintomas e as complicações da doença.

Devido à alta freqüência na população e pelo tratamento simples, seria interessante iniciar a triagem de toda a população para se detectar os afetados e realizar o tratamento preventivo. Várias metodologias têm sido utilizadas na detecção de doenças hereditárias e também na análise da $\mathrm{HH}$ seria interessante o desenvolvimento de metodologias que diminuíssem o custo e agilizassem 0 diagnóstico preciso da doença. Isto possibilitaria uma triagem mais ampla na população, permitindo a identificação precoce da doença e minimizando os custos de pacientes que são diagnosticados tardiamente.

\section{Materiais e métodos}

\section{Aná lise das a mostras}

Foram analisadas 289 amostras de indivíduos de naturalidade paranaense, cujo fenótipo está relacionado à origem caucasóide desta população, com consentimento prévio informado, seguindo as normas legais. Destas, 129 amostras foram obtidas no campus da PUCPR e coletadas através de uma picada, com lanceta automática (AccuChek $^{\circledR}$, da Softclix ${ }^{\circledR}$ ), na ponta de um dos dedos da mão. O sangue foi depositado em papel filtro, conservando o DNA do voluntário sem risco de contaminação, com redução de custo e tempo da análise. Também se utilizaram 160 amostras de DNA já purificadas, com as mesmas características étnicas, doadas pelo laboratório Genetika, para complementação do número de amostras.

\section{PCR, SSCP e RFLP}

Para análise do material genético fez-se uso da técnica de PCR - Reação em Cadeia pela Polimerase, que é a amplificação de regiões específicas do DNA. Esta técnica permite a amplificação de fragmentos desde 50 pares de bases até mais de 3000 pares de bases. A PCR consiste em três fases: a) Desnaturação, onde por aquecimento a dupla fita é aberta; b) Hibridação, onde oligonucleotídeos iniciadores (primers) complementares a uma seqüência de DNA-alvo encontram esta seqüência específica; c) Extensão ou Polimerização da cadeia de DNA, que ocorre sob ação da Taq polimerase (enzima extraída de uma bactéria termofílica, a Thermus aquaticus), a uma temperatura de $72^{\circ} \mathrm{C}$.

Para a PCR, os reagentes utilizados foram: água bidestilada, tampão de reação 10x [200mM Tris$\mathrm{HCl}(\mathrm{pH} 8,4) ; 500 \mathrm{mM} \mathrm{KCl}] 2,5 \mathrm{mM} \mathrm{MgCl}_{2} ; 0,2 \mathrm{mM}$ de cada DNTP; 50pmol de cada primer específico para amplificação do éxon 3 (C282Y 1: 5'CCTCTCCTCATCATCCTTCC-3'; C282Y 2: 5'CCCAGGGGGTACAGCCA-3') e 1,5U de Taq DNA Polimerase, em um volume final de $50 \mathrm{ml}$. A cada tubo foram adicionados $2 \mathrm{ml}$ da amostra de DNA ou $1 \mathrm{~mm}^{2}$ de papel filtro. Através da metodologia descrita por Raskin et al.(1993) as amostras foram submetidas, antes da PCR propriamente dita, a 3 ciclos prévios de aumento e diminuição da temperatura a $94^{\circ} \mathrm{C}$ e $4^{\circ} \mathrm{C}$, a fim de promover a ruptura das células, facilitando a liberação do DNA. Tanto as amostras de DNA quanto às de papel filtro passaram por PCR nas seguintes condições: $96^{\circ} \mathrm{C}$ por $3 \mathrm{~min}$, para desnaturação completa das amostras; em seguida a temperatura foi reduzida para $80^{\circ} \mathrm{C}$ para que a Taq Polimerase fosse adicionada. A isto se seguiram 40 ciclos de $92^{\circ} \mathrm{C}$ por $1^{\prime}, 58^{\circ} \mathrm{C}$ por $30^{\prime \prime}$ e $72^{\circ} \mathrm{C}$ por $1^{\prime}$. Após o término dos ciclos, houve uma extensão final a $72^{\circ} \mathrm{C}$ por $10 \mathrm{~min}$. Ao fim da reação, procedeu-se à detecção do produto de PCR amplificado através de eletroforese vertical, em $150 \mathrm{~V}$ por uma hora e meia em gel de poliacrilamida $10 \%$, imerso 
em tampão TBE 1X. Adicionou-se em cada poço do gel $7 \mathrm{ml}$ do produto de PCR mais $2 \mathrm{ml}$ de corante com azul de bromofenol. Aplicou-se um marcador de massa molecular de 100pb no final do gel para inferência do tamanho aproximado dos fragmentos gerados nas PCRs. Foi detectado um fragmento de $400 \mathrm{pb}$ visualizado sob luz ultravioleta pela coloração com brometo de etídio.

A técnica de SSCP - Polimorfismo Conformacional de Fita Simples é uma técnica de rastreamento de mutações geralmente subseqüente a uma PCR, que permite uma detecção rápida e sensível da maior parte das mutações de um gene. Ela é baseada na amplificação de regiões específicas, seguida por desnaturação dos produtos e eletroforese em gel de acrilamida (ORITA et al.,1989). Consiste numa desnaturação do DNA por calor a $92^{\circ}$ por $4^{\prime}$, que permite a abertura da dupla fita e colocação rápida no gelo, evitando assim a renaturação da dupla fita e permitindo pareamentos na própria fita, formando estruturas tridimensionais específicas nesta. Este produto de PCR é posteriormente corrido em gel não desnaturante, por 28 horas, e corado com prata (SAMMONS et al.,1981). A grande vantagem desta técnica é que quase todas as alterações na seqüência de bases do fragmento amplificado, entre 50 e 400 pares de bases podem ser detectados por desvios de mobilidade no gel sem necessitar do uso de enzimas de restrição ou sondas alelo-específicas, com uma confiabilidade de $98 \%$.

A técnica de RFLP-Polimorfismo no Comprimento de Fragmentos de Restrição é baseada na utilização de enzimas específicas. Elas reconhecem seqüências específicas de nucleotídeos, cortando a fita dupla em locais denominados sítios de restrição. Para a mutação C282Y, as enzimas utilizadas foram SAU3AI e MBOI que foram incubadas com o produto de PCR a uma temperatura de $42^{\circ} \mathrm{C}$ overnight. A presença do sítio de restrição era encontrado em alelos mutantes conforme Figura 1.

\section{Análise estatística}

As freqüências alélicas e genotípicas foram calculadas usando a contagem direta.

\section{Resulta dos e Discussão}

A investigação da mutação C282Y, presente no terceiro éxon do gene HFE, indicou num total de 289 amostras, uma freqüência genotípica de $96,5 \%$ homozigotos normais $(n=279), 0,3 \%$ homozigotos mutados ( $n=1$ ) e 3,2\% heterozigotos $(\mathrm{n}=9)$. Os padrões encontrados pela técnica SSCP para indivíduos homozigotos normais ou heterozigotos estão representados na Figura 2.

O presente estudo demonstra a existência de diferenças regionais da mutação C282Y quando comparada a outras populações de acordo com a Tabela 1. Na população de origem caucasóide, a freqüência estimada de homozigotos mutados é de 1:300 e, portanto, na população paranaense os dados encontrados para estes indivíduos estão de acordo com a literatura. Os dados demonstram que dos 289 indivíduos analisados, 1 é homozigoto $(0,3 \%)$ para a mutação C282Y, o que se aproxima da proporção esperada de 1:300. Foram encontrados 9 indivíduos heterozigotos (3,2\%).

Nesta amostra da população paranaense 96,5\% dos indivíduos são homozigotos normais, $0,3 \%$ são homozigotos mutados e 3,2\% heterozigotos $\mathrm{C} 282 \mathrm{Y}$. Comparando as freqüências encontradas na população paranaense com a população da Alemanha e Itália, nota-se que estas são muito semelhantes, o que se confirma com a grande quantidade de descendentes dessas populações no Paraná.

A sobrecarga de ferro é diagnosticada levando em conta três parâmetros bioquímicos: níveis de ferro sérico, saturação de transferrina e ferritina sérica. A HH é conseqüência da sobrecarga primária de ferro devida a uma absorção excessiva pelas células e, na maioria dos casos, o diagnóstico definitivo requer a realização de uma biópsia hepática. Porém, a recente caracterização do gene HFE e a demonstração de que mutações neste gene estão associadas ao desenvolvimento da doença, abrem a possibilidade, em alguns casos, de estabelecer um diagnóstico molecular que substitua a biópsia hepática. Desta forma, a biópsia hepática ficaria então restrita aos casos nos quais houvesse suspeita significativa de uma sobrecarga de ferro suficientemente grande que possibilitasse a existência de dano hepático como cirrose ou fibrose e o teste molecular para $\mathrm{C} 282 \mathrm{Y}$ fosse negativo.

Embora não existam dúvidas de que a mutação C282Y cause $\mathrm{HH}$, há uma grande variabilidade de manifestações clínicas nos indivíduos homozigotos e heterozigotos explicada pela penetrância incompleta da mutação. Por isso, a 
pesquisa da mutação C282Y permite identificar os homozigotos e afirmar, com grande probabilidade de acerto, que, na ausência de perdas sanguíneas, eles desenvolverão sobrecarga de ferro, enquanto que nos heterozigotos $\mathrm{C} 282 \mathrm{Y}$ ou heterozigotos compostos (C282Y/H63D) esse risco é menor. É interessante enfatizar também que, outros estudos têm mostrado que a sobrecarga de ferro em pacientes com $\mathrm{HH}$ é maior em $\mathrm{C} 282 \mathrm{Y}$ homozigotos quando comparada a heterozigotos compostos. Além disso, para a mutação C282Y, a condição de heterozigoto composto produz fenótipos suaves da doença enquanto que a homozigosidade está relacionada a sintomas mais severos.

Tendo em vista a grande heterogeneidade genética da população do Brasil, é necessária uma triagem de outras frações desta, já que se conclui que as diferentes freqüências da mutação C282Y estão relacionadas com as diferenças regionais no país. Através do desenvolvimento da análise do gene HFE com a caracterização da freqüência da mutação C282Y na população paranaense, percebe-se que o prévio diagnóstico da $\mathrm{HH}$ através da análise molecular seria extremamente vantajoso, tanto no aspecto social (com menos gasto por parte do governo no tratamento de afetados) como no aspecto individual (evitando o aparecimento de sintomas clínicos em indivíduos afetados). Visto que a freqüência desta mutação é alta, a triagem da população permitiria a prévia detecção da doença, aumentando, assim, a qualidade de vida dos indivíduos afetados.

Tabela 1: Freqüências genotípicas para a mutação C282Y na população geral

\begin{tabular}{|c|c|c|c|c|}
\hline \multirow{2}{*}{\multicolumn{2}{|c|}{ População }} & $\mathbf{N .}^{0}$ & C282Y homozigoto & C282Y heterozigoto \\
\hline & & amostral & & \\
\hline & os Unidos & $n=3353$ & $0-1 \%$ & $1,8 \%-13 \%$ \\
\hline & 'anadá & $n=1084$ & $0-0,3 \%$ & $8,4 \%-8,6 \%$ \\
\hline & glaterra & $n=469$ & $0,5 \%-1 \%$ & $5,9 \%-7,6 \%$ \\
\hline & rança & $\mathrm{n}=644$ & $0-0,8 \%$ & $1 \%-6 \%$ \\
\hline & emanha & $n=268$ & Ausente & $3,3 \%-7 \%$ \\
\hline & Itália & $n=230$ & Ausente & $1,1 \%-2,2 \%$ \\
\hline & ustrália & $\mathrm{n}=189$ & Ausente & Ausente \\
\hline & Africa & $n=483$ & Ausente & $0-0,5 \%$ \\
\hline Aborí & es australianos & $n=93$ & Ausente & Ausente \\
\hline \multirow[t]{2}{*}{ Brasil } & Região Sudeste $^{1}$ & $n=160$ & Ausente & $4,4 \%$ \\
\hline & Região Sul & $\mathrm{n}=289$ & $0,3 \%$ & $3,2 \%$ \\
\hline
\end{tabular}

NOTA: ${ }^{1}$ População de Ribeirão Preto, SP. (CALADO et al.,2000).

FONTE: HANSON et al. (2001). 


\section{Figura 1: Padrões resultantes da digestã o com enzimas de restrição.}

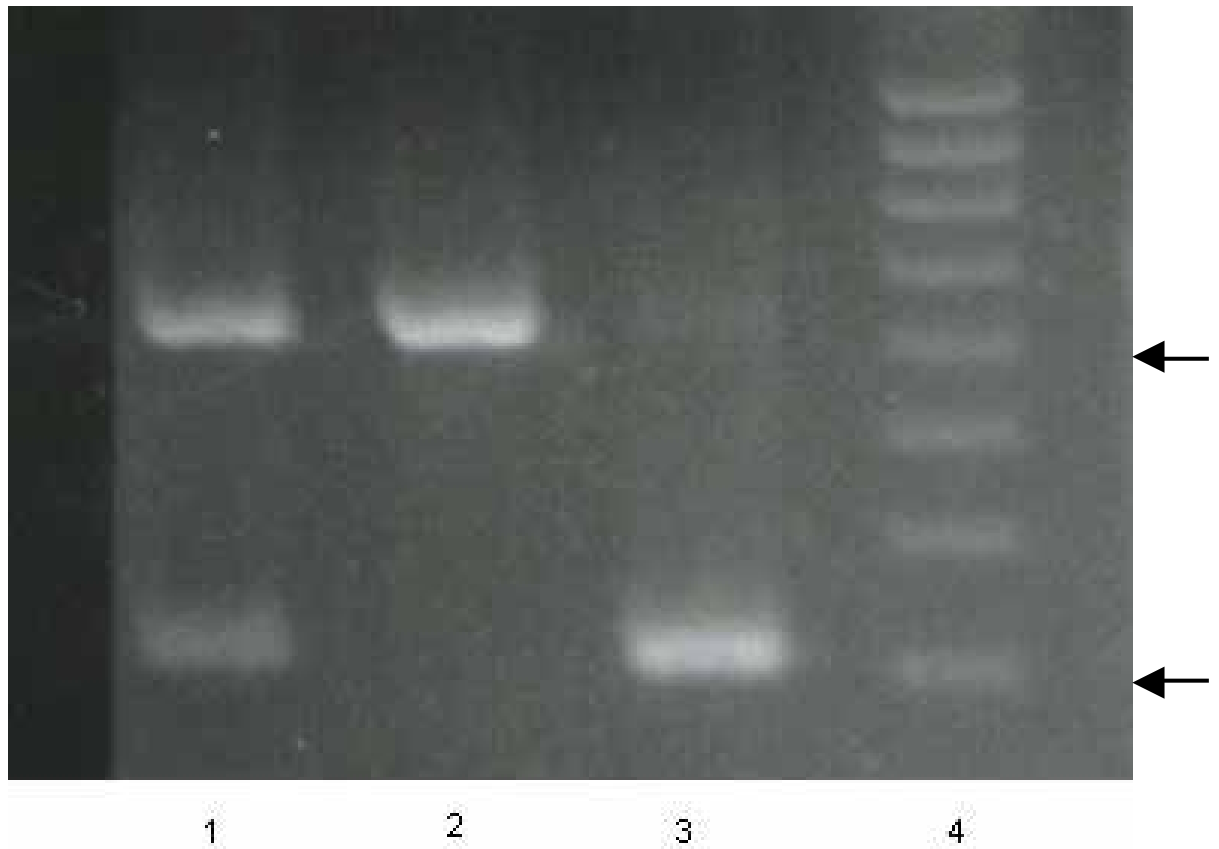

NOTA: 1- heterozigoto; 2- homozigoto normal; 3- homozigoto mutado; 4- marcador de massa molecular de 50pb. A seta superior indica 0 fragmento de $400 \mathrm{pb}$, enquanto que a seta inferior indica o fragmento de $250 \mathrm{pb}$. Gel de agarose 1,2\% corado com brometo de etídio FONTE: Os autores.

\section{Figura 2: Padrões encontrados para a mutação C282Y.}

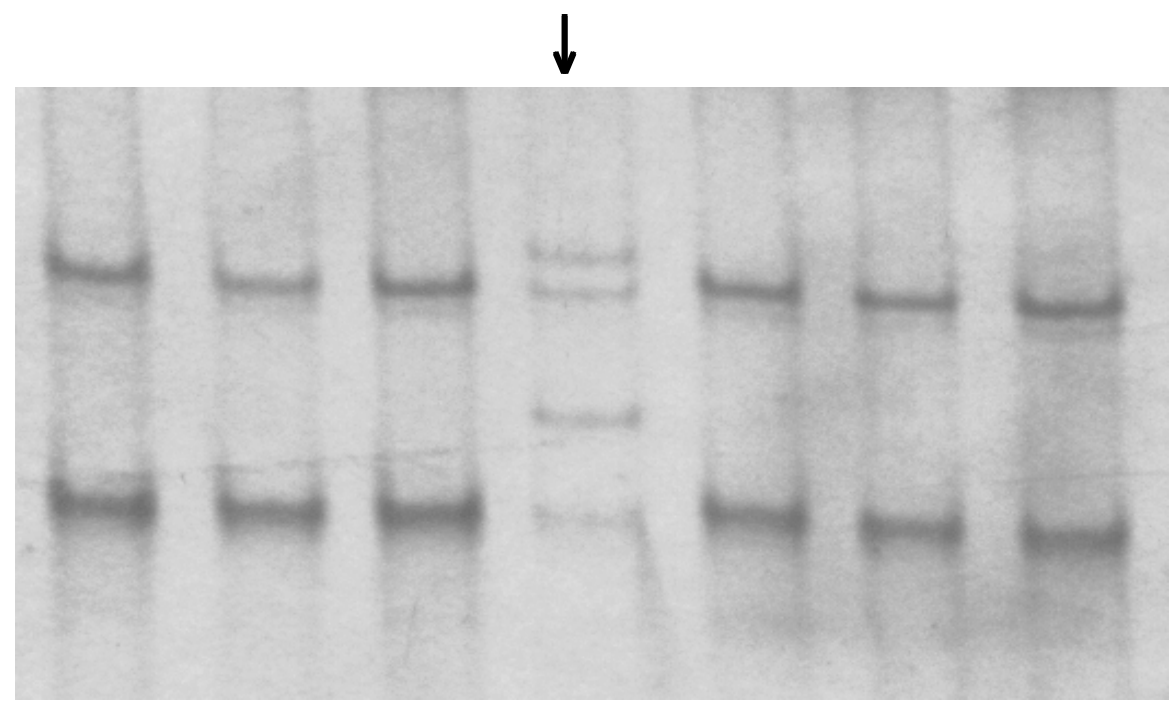

NOTA: A seta indica o padrão heterozigoto alelo selvagem/mutação C282Y. Gel de poliacrilamida 10\% corado com prata. Todos os outros padrões são homozigotos normais alelo selvagem/selvagem

FONTE: Os autores. 


\section{Referências}

BACON, B.R; POWELL, L.W; ADAMS, P.C; KRESINA, T.F; HOOFNAGLE, J.H. Molecular medicine and hemochromatosis at the crossroads. Gastroenterology, v. 116, p.193-207, 1999.

BITTENCOURT, P.L; PALACIOS, S.A; COUTO, C.A; CANCADO, E.L; CARRILHO, F.J; LAUDANNA, A.A; KALIL, J; GAYOTTO, L.C; GOLDBERG, A.C. Analysis of HLA-A antigens and C282Y and H63D mutations of the HFE gene in Brazilian patients with hemochromatosis. Braz J Med Biol Res, v. 35, p. 329-335, 2002.

CALADO, R.T; FRANCO, R.F; PAZIN-FILHO, A; SIMOES, M.V; MARIN-NETO, J.A; ZAGO, M.A. HFE gene mutations in coronary atherothrombotic disease. Braz J Med Biol Res, v. 33, n. 3, p. 301-6, 2000.

CONNOR, J.R; MILWARD, E.A; MOALEM, S; SAMPIETRO, M; BOYER, P; PERCY, M.E; VERGANI, C; SCOTT, R.J; CHORNEY, M. Is hemochromatosis a risk factor for Alzheimer's disease?J Alzheimers Dis, v. 3, n. 5, p. 471-477, 2001.

FEDER, J.N; GNIRKE, A; THOMAS, W; TSUCHIHASHI, Z; RUDDY, D.A; BASAVA, A; DORMISHIAN, F; DOMINGO, R. JR; ELUIS, M.C; FULIAN, A; HINTON, LM; JONES, N.L; KIMMEL, B.E; KRONMAL, G.S; LAUER, P; LEE, V.K; LOEB, D.B; MAPA, F.A; MCCLELLAND, E; MEYER, N.C; MINTIER, G.A; MOELLER, N; MOORE, T; MORIKANG, E; WOLFF, R.K. A novel MHC class Ilike gene is mutated in patients with hereditary haemochromatosis. Nat Genet, v. 13, n. 4, p. 399408, 1996.

GOCHEE, P.A; POWELL, L.W. What's new in hemochromatosis. Curr Opin Hematol, v. 8, n. 2, 98-104, 2001.

HANSON, E.H; IMPERATORE, G; BURKE, W. HFE gene and hereditary hemochromatosis: a HuGE review. Human Genome Epidemiology. Am J Epidemiol, v. 1, n. 154(3), p. 193-206, 2001.

IKEDA, M. Iron overload without the C282Y mutation in patients with epilepsy. J Neurol Neurosurg Psychiatry, v. 70, n. 4, p. 551-3, 2001.

LEBRON, J.A; BENNETT, M.J; VAUGHN, D.E; CHIRINO, A.J; SNOW, P.M; MINTIER, G.A; FEDER,
J.N; BJORKMAN, P.J. Crystal structure of the hemochromatosis protein HFE and characterization of its interaction with transferrin receptor. Cell, v. 3, n. 93(1), p. 111-23, 1998.

LYON, E; FRANK E.L. Hereditary hemochromatosis since discovery of the HFE gene. Clinical Chemistry, v. 47, n. 7, p. 1147-1156, 2001.

MERRYWEATHER-CLARKE, A.T; POINTON, J.J; SHEARMAN, J.D; ROBSON, K.J. Global prevalence of putative haemochromatosis mutations. J Med Genet, v. 34, p. 275-278, 1997.

MOIRAND, R, ADAMS, P.C; BICHELER, V; BRISSOT, P; DEUGNIER, Y. Clinical features of genetic hemochromatosis in women compared with men. Ann Intern Medical, v. 127, p.105110, 1997.

NIEDERAU, C; FISCHER, R; PURSCHEL, A; STREMMEL, J.D; HAUSSINGER, D; STROHMEYER, G. Long-term survival in patients with hereditary hemochromatosis. Gastroenterology, v. 110, p. 1107-1119, 1996.

ORITA, M; IWAHANA, H; KANAZAWA, H; HAYASHI, K; SEKIYA, T. Detection of polymorphisms of human DNA by gel electrophoresis as single-strand conformation polymorphisms. Proc Natl Acad Sci USA, v. 8, p. 2766-70, 1989.

PIPERNO, A; AROSIO, C; FOSSATI, L; VIGANO, M; TROMBINI, P; VERGANI, A; MANCIA, G. Two novel nonsense mutations of HFE gene in five unrelated Italian patients with hemochromatosis. Gastroenterology, v. 119, p. 441-445, 2000.

POWELL, L.W. Genetics diagnosis of hemochromatosis: implications for prophylaxis and treatment. In: Arroyo, V; Bosch, J; Bruguera, M; editors. Therapy in liver diseases, Barcelona: Masson, p. 391-404, 1999.

RASKIN, S; PHILLIPS, J.A. 3. ${ }^{\text {RD }}$ KRISHNAMANI, M.R; VNENCAK-JONES, C; PARKER, R.A; ROZOV, T; CARDIERI, J.M; MARO STICA, P; ABREU, F; GIUGLIANI, R. DNA analysis of cystic fibrosis in Brazil by direct PCRamplification from Guthrie cards. Am J Med Genet, v. 1, n. 46(6), p. 665-669, 1993.

SAMMONS, D.W; ADAMS, LD; NISHIZAWA, E.E. Silver staining in PAGE. Electrophoresis, v. 2, p. 135-141, 1981. 